\title{
Axillary ultrasound and fine needle aspiration biopsy in the preoperative diagnosis of axillary metastases in early-stage breast cancer
}

\author{
XIN HU* ${ }^{*}$ XIAO ZHOU* ${ }^{*}$ HUAWEI YANG, WEI WEI, YI JIANG and JIANLUN LIU \\ Department of Breast Surgery, The Affiliated Tumor Hospital of Guangxi Medical University, \\ Nanning, Guangxi 530021, P.R. China
}

Received September 17, 2017; Accepted February 13, 2018

DOI: $10.3892 / 01.2018 .8445$

\begin{abstract}
The efficacy of axillary lymph node dissection (ALND) following sentinel lymph node biopsy (SLNB) has been questioned. The present study was performed to determine the sensitivity, specificity and accuracy of axillary ultrasound (US) and fine needle aspiration biopsy (FNAB) in the diagnosis of axillary metastases in patients with early breast cancer. A total of 214 patients with stage I and II breast cancer between June 2015 and January 2017 were included. All of the patients received axillary US as a primary investigation for lymph node status. US-guided FNAB was performed on suspicious lymph nodes. Those with non-suspicious and FNAB-negative axillary nodes proceeded to SLNB at the time of primary breast surgery. ALND was performed when the result of the US-guided FNAB was positive. The results of US and cytology were compared to histopathological results to determine their sensitivity, specificity, positive and negative predictive value and accuracy. A total of 76 out of 214 patients $(35.5 \%)$ had axillary lymph node metastases at final histology. The sensitivity and specificity of axillary US alone were $59.2 \%$ (45/76) and 78.3\% (108/138), respectively. Axillary US with FNAB identified 32 patients with positive lymph node metastases, and increased the sensitivity and specificity to $71.1 \%$ (32/45) and 100.0\% (30/30). Combined with FNAB, the positive and negative predictive values were $100.0 \%(32 / 32)$ and $69.8 \%$ (30/43), respectively. Axillary US-alone or combined US/FNAB had a high accuracy rate and a satisfactory result
\end{abstract}

Correspondence to: Professor Yi Jiang or Dr Jianlun Liu, Department of Breast Surgery, The Affiliated Tumor Hospital of Guangxi Medical University, 71 Hedi Road, Nanning, Guangxi 530021, P.R. China

E-mail: cat7921@sina.com

E-mail: jianlunliu@hotmail.com

${ }^{*}$ Contributed equally

Key words: breast cancer, axillary ultrasound, fine needle aspiration biopsy, sentinel lymph node biopsy as they cost less and it is easy to assess the status of axillary lymph nodes. Thus, axillary US with FNAB may avoid unnecessary SLNB in a significant number of patients.

\section{Introduction}

The crucial prognostic factor for breast carcinoma is still axillary lymph nodes (ALNs) metastasis $(1,2)$, and the status of ALNs can influence the effect of adjuvant therapy and surgery. Because of increased consciousness and advanced imaging modalities, breast cancer can be diagnosed earlier, and many patients have clinically negative axillae (3).

Earlier axillary lymph node dissection (ALND) was the criterion for detecting axillary metastasis. But with the advent of sentinel lymph node biopsy (SLNB), which was regarded as a better imaging and minimal biopsy method, ALND was no longer considered as the only way to detect axillary metastasis. Now SLNB is the gold standard for histopathological staging of early breast cancer, because information on ALNs status can be obtained at a lower complication rate (4). However, the location of the sentinel lymph node can be identified by preoperative lymphoscintigraphy or using blue-dye, which will increase surgical costs. Furthermore, clinical complications may occur, including allergic reactions, lower sensitivity and strength of the ipsilateral upper limb and even the uncommon occurrence of lymphedema $(5,6)$.

Axillary ultrasound (US) is a major non-surgical approach to assess ALNs (7). Particularly when using morphological criteria to detect axillary metastasis, it is moderately sensitive (8). However, axillary US is operator-dependent and machine-dependent. When only US is used to assess ALNs, the sensitivity and specificity vary greatly $(9,10)$. Therefore, in order to solve this problem, US-guided fine needle aspiration biopsy (FNAB) is required. With the application of FNAB in suspicious lymph nodes, the specificity of detecting metastatic lymph nodes can be increased $(11,12)$. Recent studies show that $7.8-16.2 \%$ of patients with axillary metastasis have been successfully diagnosed preoperatively via US-guided FNAB $(12,13)$.

Some clinical trials such as the BOOG 2013-08 (14), NCT 01821768 (15), and the SOUND (16) have been conducted recently, and breast cancer patients with negative US/FNAB 
findings were randomly assigned to SLNB and non-SLNB groups. These clinical trials demonstrated that it was necessary to perform SLNB in patients with negative US-guided FNAB of suspicious lymph nodes. A number of diagnostic tools were used to determine the status of negative ALNs in these trials, such as axillary palpation, axillary US, computed tomography (CT), or intervening suspicious lymph nodes with FNAB. Therefore, an accurate evaluation of ALNs status before surgery was an important condition to omit SLNB or ALND. The aim of the present study was to evaluate the efficiency of preoperative diagnostic techniques for ALNs status.

\section{Materials and methods}

Patient selection criteria. All the patients with stage I and II early breast cancer presenting to the Affiliated Tumor Hospital of Guangxi Medical University from June 2015 to January 2017 were prospectively included in the present study. Patients who had a previous axillary-breast surgery or radiotherapy, inflammatory breast cancer or neo-adjuvant chemotherapy were excluded from the present study. Patient demographics, clinicopathological features, axillary US \pm FNAB findings, intraoperative SLNB findings and final axillary histopathology results were recorded.

Ethical approval was obtained from the Ethics Committee for Clinical Research of The Affiliated Tumor Hospital of Guangxi Medical University (Guangxi, China), and the study itself was performed in accordance with the Declaration of Helsinki. All patients provided written informed consent.

Radiologic technique and criteria. Axilla was scanned by three experienced radiologists using a high frequency linear $12 \mathrm{MHz}$ transducer. The criteria of US to define abnormal lymph nodes included: diffuse cortical thickening, complete or partial effacement of the fatty hilum, focal cortical bulge, round or hypoechoic nodes with short axis $>5 \mathrm{~mm}$ (Figs. 1 and 2) show the sonographic images for suspicious lymph nodes.

After evaluating the axillary lymph node status by US, a US-guided FNAB was performed by the specific radiologist using a fine-needle (22-gauge) toward the most representative abnormal node. $10 \mathrm{ml}$ of $1 \%$ xylocaine was used to achieve local anesthesia. Under US guidance, the needle was inserted into the cortex of the lymph node in a way parallel to the long axis of the probe. A minimum of three aspirations were performed when the needle tip was confirmed to be inserted into the target area. The aspirate was then sent to a cytopathologist for subsequent analysis.

Pathologic technique. The aspirated material was smeared and fixed with $95 \%$ alcohol, then smears were stained with Papanicolaou and Giemsa procedures. The samples were examined by an experienced pathologist and were divided into four groups: Benign, suspicious for malignancy, malignant, and inadequate for evaluation. In the assessment of US-guided FNAB accuracy, malignant sampling on FNAB was regarded as positive. Benign, suspicious for malignancy and insufficient sampling were regarded as negative results in the present study.

Surgical technique. The patients who were diagnosed with positive FNAB underwent directly ALND after they decided

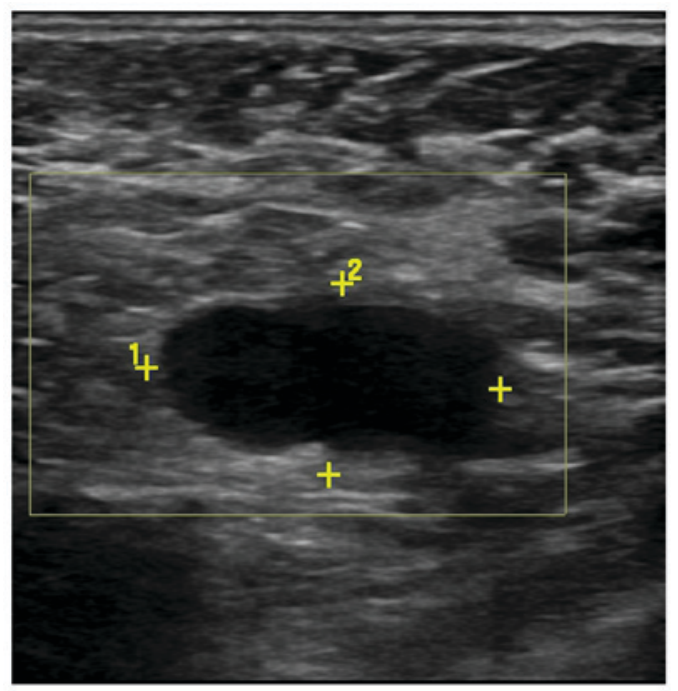

Figure 1. Scans of the left axillary lymph node from a 46-year-old female patient with invasive ductal carcinoma. Grayscale sonography showed diffusely enlarged lymph node with effaced fatty hilum.

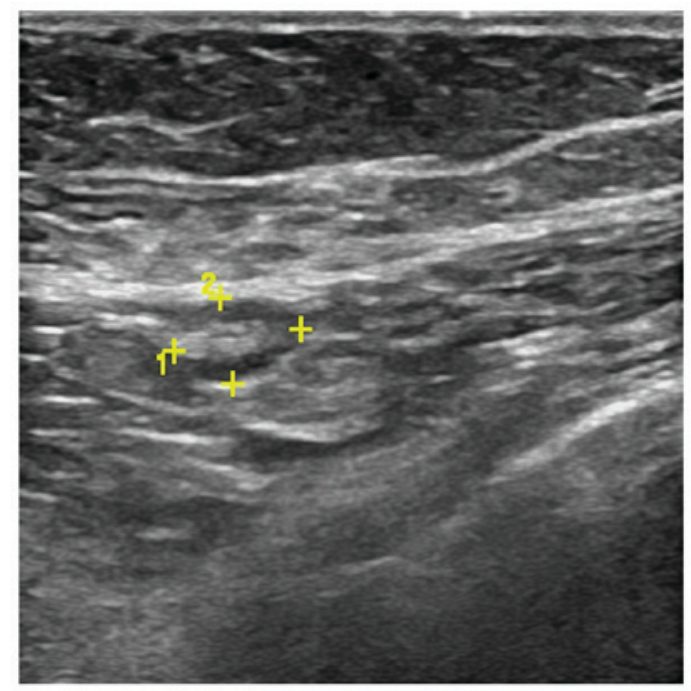

Figure 2. Scans of the left axillary lymph node from a 52-year-old female patient with invasive ductal carcinoma. Grayscale sonography showed the lymph node with focal cortical bulge.

to have an operation. For a negative axillary US or a negative FNAB, a SLNB procedure was performed using blue-dye or radiocolloid injection. Similarly, if a positive node was found by SLNB or if there were no sentinel lymph nodes detected intraoperatively, then ALND was performed. All lymph node tissues, together with breast samples, were sent to the laboratory for final histopathological examination. (Fig. 3) depicts the procedure for the perioperative diagnosis of axillary metastasis.

Statistical analysis. Axillary US results and the cytological findings of FNAB were further identified by the final histological findings. The sensitivity, specificity, positive predictive value (PPV), negative predictive value (NPV) and accuracy of axillary US and FNAB were computed. An exact $95 \%$ confidence interval (CI) was calculated on the basis of the binomial 


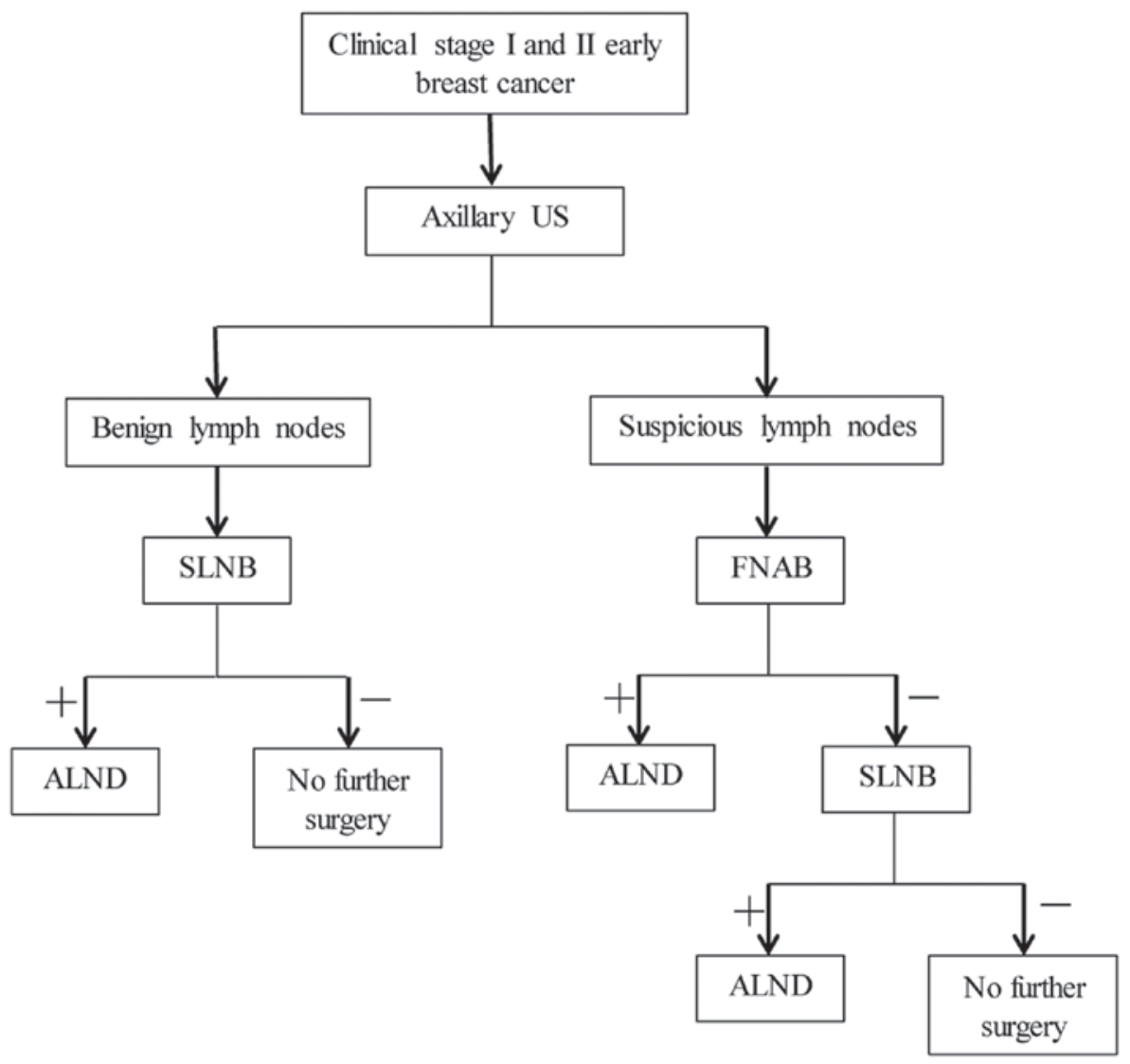

Figure 3. Schematic of perioperative diagnosis of axillary metastasis. US, ultrasound; SLNB, sentinel lymph node biopsy; FNAB, fine needle aspiration biopsy; ALND, axillary lymph node dissection.

distribution. The P-values below 0.05 were considered to be statistically significant. Statistical analyses were performed using Statistical Product and Service Solutions version 17.0 Windows (SPSS, Inc., Chicago, IL, USA) and MedCalc software (MedCalc Software, Mariakerke, Belgium), and Fisher's exact or a Chi-square test were performed.

\section{Results}

Patients and tumour characteristics. There were 476 patients with invasive breast cancer included in this continuous study between June 2015 and January 2017. Out of which 214 patients were stage I and II early breast cancer and underwent axillary US prior to definitive surgery. The histopathologic and demographic features of these patients were compared with final axillary histopathology reports (Table I).

The median patient age was 52 years (range 28-72) in the present study. There were 171 invasive ductal carcinomas, 24 invasive lobular carcinomas and 19 other histological types (invasive mucinous, medullary, tubular, and mixed carcinoma) (17). The right ALNs were detected by US in 99 patients, and the left ALNs were detected by US in 115 patients. Of the 214 primary breast cancer patients, ninety-three cases were of grade I, and 121 cases were of grade II. In the final histopathology reports, $44.4 \%$ patients (76/171) had positive lymph nodes in patients with invasive ductal carcinoma. However, no positive lymph nodes were found in other histological types. The present study showed that there was a statistically significant difference in the histopathological ALNs involvement rate between different histological types $(\mathrm{P}<0.001)$. In addition, the final histopathology reports differed significantly with respect to Her-2/neu status $(\mathrm{P}<0.001)$.

Axillary US results. As shown in (Table II), there were 75 patients with suspicious ALNs diagnosed by pre-operative axillary US, while the remaining 139 patients were sonographically benign. Seventy-six patients $(35.5 \%)$ were diagnosed with metastatic disease in the final histopathology reports. Of these 76 positive cases, the result of axillary US was suspicious for malignancy in 45 cases (59.2\%). Furthermore, the comparison between the accuracy of axillary US and the final histopathology reports of ALNs by SLNB or ALND was shown in (Table III). The sensitivity, specificity, PPV, and NPV of axillary US alone were 59.2\% (45/76), 78.3\% (108/138), 60.0\% $(45 / 75)$, and $77.7 \%(108 / 139)$ respectively. False negative rate for axillary US was $22.3 \%$ (31/139). The whole diagnostic accuracy for axillary US was 71.5\% (153/214).

US-guided FNAB results. In the present study, all the patients with suspicious ALNs on axillary US were performed FNAB. Of these 75 patients, $32(42.7 \%)$ were confirmed to have malignant cytology on FNAB. $42.7 \%$ of the patients underwent ALND directly instead of the SLNB procedure.

Table II showed the axillary findings of cytology and histopathology. All 32 patients with positive FNABs had axillary metastases in the final ALNs histopathological report. 
Table I. Comparison of the patients demographic and tumor characteristics with final axillary histopathology results ( $\mathrm{n}=214)$.

\begin{tabular}{|c|c|c|c|}
\hline Characteristic & Axilla (+) (\%) & Axilla (-) (\%) & P-value \\
\hline Age (years) & & & 0.189 \\
\hline$\leq 50$ & $25(32.9)$ & $58(42.0)$ & \\
\hline$>50$ & $51(67.1)$ & $80(58.0)$ & \\
\hline Axillary side & & & 0.271 \\
\hline Left & $37(48.7)$ & $78(56.5)$ & \\
\hline Right & $39(51.3)$ & $60(43.5)$ & \\
\hline cT stage & & & 0.898 \\
\hline $\mathrm{T} 1$ & $34(44.7)$ & $63(45.7)$ & \\
\hline $\mathrm{T} 2$ & $42(55.3)$ & $75(54.3)$ & \\
\hline cN stage & & & 0.074 \\
\hline No & $57(75.0)$ & $87(63.0)$ & \\
\hline $\mathrm{N}+$ & $19(25.0)$ & $51(37.0)$ & \\
\hline Clinical stage & & & 0.559 \\
\hline I & $31(40.8)$ & $62(44.9)$ & \\
\hline $\mathrm{IIA}+\mathrm{IIB}$ & $45(59.2)$ & $76(55.1)$ & \\
\hline Primar tumor histology & & & $<0.001^{\mathrm{a}}$ \\
\hline Invasive ductal carcinoma & $76(100.0)$ & $95(68.8)$ & \\
\hline Invasive lobular carcinoma & $0(0.0)$ & $24(17.4)$ & \\
\hline Other & $0(0.0)$ & $19(13.8)$ & \\
\hline Surgery & & & 0.143 \\
\hline $\mathrm{BCS}$ & $29(38.2)$ & $67(48.6)$ & \\
\hline Mastectomy & $47(61.8)$ & $71(51.4)$ & \\
\hline ER status & & & 0.761 \\
\hline Negative $(<1 \%)$ & $20(26.3)$ & $39(28.3)$ & \\
\hline Positive $(\geq 1 \%)$ & $56(73.7)$ & 99 (71.7) & \\
\hline PR status & & & 0.677 \\
\hline Negative $(<1 \%)$ & $20(26.3)$ & $40(29.0)$ & \\
\hline Positive $(\geq 1 \%)$ & $56(73.7)$ & $98(71.0)$ & \\
\hline Her $2 /$ neu status & & & $<0.001^{\mathrm{a}}$ \\
\hline Negative $(0,1+, 2+$ FISH not amplified $)$ & $33(43.4)$ & $114(82.6)$ & \\
\hline Positive $(3+, 2+$ FISH amplified $)$ & $43(56.6)$ & $24(17.4)$ & \\
\hline Proliferative index & & & 0.950 \\
\hline $\mathrm{Ki}-67(<15 \%)$ & $24(31.6)$ & $43(31.2)$ & \\
\hline Ki-67 ( $\geq 15 \%)$ & $52(68.4)$ & $95(68.8)$ & \\
\hline
\end{tabular}

${ }^{a} \mathrm{P}<0.05$. Data are presented as the n number (\%). BCS, breast-conserving surgery; ER, estrogen receptor; PR, progesterone receptor; FISH, fluorescence in situ hybridization; Her2, human epidermal growth factor receptor 2; cT, clinical tumor stage; cN, clinical node stage.

Table II. Association between axillary ultrasound, ultrasound-guided fine needle aspiration biopsy with final histopathology.

\begin{tabular}{|c|c|c|c|c|}
\hline \multirow[b]{2}{*}{ Investigation } & \multirow[b]{2}{*}{ Category } & \multicolumn{2}{|c|}{ Final histopathology } & \multirow[b]{2}{*}{ Total (n) } \\
\hline & & Positive & Negative & \\
\hline \multirow[t]{3}{*}{ Axillary US } & Suspicious & $45(60.0 \%)$ & $30(40.0 \%)$ & 75 \\
\hline & Benign & $31(22.3 \%)$ & $108(77.7 \%)$ & 139 \\
\hline & Total (n) & 76 & 138 & 214 \\
\hline \multirow[t]{3}{*}{ US-guided FNAB } & Positive & $32(100.0 \%)$ & $0(0.0 \%)$ & 32 \\
\hline & Negative & $13(30.2 \%)$ & $30(69.8 \%)$ & 43 \\
\hline & Total (n) & 45 & 30 & 75 \\
\hline
\end{tabular}

Data are presented as the $\mathrm{n}$ number $(\%)$. FNAB, fine needle aspiration biopsy; US, ultrasound. 
Table III. Accuracy of axillary ultrasound and ultrasoundguided fine needle aspiration biopsy.

\begin{tabular}{lccrrr}
\hline & \multicolumn{2}{c}{ Axillary US } & & \multicolumn{2}{c}{ US-guided FNAB } \\
\cline { 2 - 3 } \cline { 6 - 6 } Variable & $\%$ & $95 \% \mathrm{CI}$ & & $\%$ & $95 \% \mathrm{CI}$ \\
\hline Sensitivity & 59.2 & $47.3-70.4$ & & 71.1 & $55.7-83.6$ \\
Specificity & 78.3 & $70.4-84.8$ & & 100.0 & $88.4-100.0$ \\
PPV & 60.0 & $48.0-71.2$ & & 100.0 & $89.1-100.0$ \\
NPV & 77.7 & $69.9-84.3$ & & 69.8 & $53.9-82.8$ \\
Accuracy & 71.5 & $64.7-79.1$ & & 82.7 & $71.7-90.8$ \\
Total (n) & & 214 & & \multicolumn{2}{c}{75} \\
\hline
\end{tabular}

CI, confidence interval; FNAB, fine needle aspiration biopsy; NPV, negative predictive value; PPV, positive predictive value; US, ultrasound.

Negative FNABs were found in 43 patients, 13 of which (30.2\%) had positive results after SLNB or axillary dissection.

The diagnostic power of FNAB which was used to identify metastatic ALNs was statistically analyzed. In predicting ALNs status, the sensitivity, specificity, PPV, and NPV of US-guided FNAB were $71.1 \%$ (32/45), 100.0\% (30/30), $100.0 \%$ (32/32), and 69.8\% (30/43), respectively. False negative rate was $30.2 \%$ (13/43). The overall diagnostic accuracy of US-guided FNAB was 82.7\% (62/75) (Table III).

SLNB results. SLNB was performed in 182 patients. A mean of 2.21 nodes were excised per patient (range 1-5 nodes). Sentinel lymph nodes were positive in 44 patients. A total of 64 sentinel lymph nodes were identified as metastases. In these patients, isolated tumor cells (ITC) were identified in 6 lymph nodes, micrometastases in 11 lymph nodes, and macrometastases in 47 lymph nodes.

\section{Discussion}

The following procedure is applied to the conventional staging of breast carcinoma: Breast and axillary US, physical examination, history, chest X-ray, abdominal CT, and bone survey. The most important parameter which can affect surgery and medical treatment in breast cancer patients is the status of the axillary lymph node. In addition, the mode of ALND depends on preoperative detection of axillary metastases.

Due to both the increased awareness of breast carcinoma and comprehensive breast screening programs, the disease is detected at an early stage at present. In this case, the possibility of patients with microscopic or clinical ALNs involvement on admission is low. Breast-conservative surgery can be performed, if there are no axillary lymph node involvement in T1 and T2 breast cancers. Preoperative neoadjuvant chemotherapy is used if distant metastases or lymph nodes metastases are detected in locally advanced breast cancer (18).

Axillary US combined with FNAB was implemented in 1997 (19). US-guided FNAB, which was an alternative technique, appeared nearly at the same time with SLNB. It has been shown that ultrasound might be used to assess lymph nodes quite accurately (20). Many studies have shown that ALNs FNAB-guided preoperative staging was more accurate. Chang et al (21) indicated that the PPV and NPV of US-guided FNAB were quite high as 98.7 and $81.8 \%$, respectively.

At present, the sentinel node dissection procedure can be skipped, and ALND is performed even in patients who have a single positive axillary lymph node $(22,23)$. Preoperative axillary US or FNAB on suspicious lymph nodes can reduce the demand for SLNB by 21- 65\%. In the present study, US-guided FNAB was used to detect axillary metastases, and the demand for SLNB was eliminated in $42.7 \%$ of the cases. If unnecessary SLNB step can be avoided, the duration of the surgery will be shortened and the costs of the procedure will be decreased markedly, resulting in a reduction in healthcare expenses by nearly $20 \%(22,24,25)$.

Leenders et al (26) reported sensitivity, specificity, PPV and NPV of axillary US alone as 60.8, 80.7, 67.5 and 70.7\%, respectively. When combining axillary US with FNAB of suspicious lymph nodes, sensitivity was $73.5 \%$, specificity was 99.9\%, PPV was $99.1 \%$ and NPV was $69.0 \%$ (26). Similarly García Fernández et al (27) demonstrated that US-guided FNAB showed PPV of $87 \%$, NPV of $82 \%$, sensitivity of $70 \%$ and specificity of $100 \%$, when compared with final axillary histology (27). The sensitivity, specificity, PPV, and NPV of axillary US alone were 59.2\% (45/76), 78.3\% (108/138), 60.0\% (45/75) and $77.7 \%$ (108/139), respectively, in the present study. This result is similar to above studies concerning the role of axillary US alone in preoperative detection of positive ALNs. However, the sensitivity and specificity of US-guided FNAB in evaluating the axillary lymph node grew to 71.1 and $100.0 \%$, respectively, after combining the axillary US with FNAB. The PPV and NPV of this method were evaluated to be 100.0 and $69.8 \%$, respectively, which was again consistent with previous studies.

Inadequate sampling was the most important cause of the false negative results found in recent studies. The proportion of insufficient sampling can be reduced when the number of aspirations was increased (23). The inadequate sampling rate was $8.5 \%$ in the present study, which was similar to the rate reported in the literature. The small size of metastatic lymph nodes and the deficient imaging of ALNs detected by US caused an inadequate aspiration $(23,28)$.

The sensitivity of US-guided FNAB is related to the number of involved ALNs. The sensitivity will increase from 47.1 to $80 \%$, if two or more lymph nodes are involved (29). Deurloo et al (30) showed that when ALNs with a cortical thickness of $>2 \mathrm{~mm}$ were selected for puncture, the sensitivity and specificity of US-guided FNAB would be increased. Studies have shown that as the tumor size increased, the number of involved lymph nodes also increased. The prognosis of small tumors with axillary involvement was superior to that of large ones (31).

In the present study, $30.2 \%$ of cases had false negative results for the axillary lymph node FNAB. The reason for the false negative results may be due to inappropriate sampling, micro-metastasis, the deficient imaging of all the lymph nodes, and mistakes in radiologic and pathologic evaluation $(22,24)$. In the case of non-diagnostic/inadequate cytology result, the biopsy should be repeated, because the proportion of positive nodes in these patients is extremely high (32). 
It has been reported that the causes of false positive results are mainly due to the insufficient sampling of ALNs or to an inaccurate assessment of cell types obtained from the puncture $(22,33)$. The enlargement of reactive lymph node is an important cause of clinically false positive assessment. To distinguish between normal and abnormal ALNs, the size of lymph nodes is not the standard to differentiate them. Fatty or reactive lymph nodes can be mistaken for metastatic disease, because they may be large enough in size (34). In the present study, the US-guided FNAB did not produce false positive results. Some studies showed that there were no false positive results for the US-guided FNAB, while another of them reported false positive results ranging from 1.4 to $1.6 \%(22,23,33,35)$.

We do not have enough evidence to suggest that the node submitted to FNAB was exactly the lymph node which was detected in subsequent axillary dissection. Abe et al (36) used thick-needle biopsy to detect axillary metastases. They reported that the positive lymph node was the only sentinel node found after SLNB or ALND, in $>15 \%$ of positive US-guided core needle biopsy cases. This indicated that the lymph node which underwent US-guided core needle biopsy was the same node detected to be histologically positive on the basis of axillary dissection. When performing FNAB, the largest node which has the most pathological morphology is usually chosen as the target. The closest lymph node from the breast is very likely to be the sentinel node. It has been reported that the sensitivity of the procedure would be increased, if the lymph node closest to the breast was performed FNAB $(36,37)$.

It is obvious that FNAB has more advantages than SLNB in case of skipped metastasis. Previous study has shown that metastatic disease may not first metastasize to level I nodes, but skip to level II nodes directly (38). FNAB can be used not only for sentinel lymph nodes, but for any lymph nodes which have sonographic malignancy standard.

An advantage of the present study is its prospective design with a consecutive series of patients treated at our hospital. Another advantage is that 3 radiologists with 5-10 years of work experience performed axillary US and FNAB. However, this is a single-center study that may have a bias related to external validity, which is a limitation of the present study. Another limitation of the present study is that it is difficult for us to perform a direct correlation between ALNs submitted to US-guided FNAB and those obtained in axillary surgery.

In conclusion, axillary US can be complementary to physical examination in axillary assessment. In addition, combining axillary US and FNAB can detect axillary metastases timely and help us plan our first surgery accordingly. Axillary US-alone or combined US/FNAB had a high accuracy rate and a satisfactory result because they cost less and are easy to assess the status of ALNs. Thanks to the excellent PPV of US-guided FNAB, ALND can be performed in patients with positive FNAB, which can avoid SLNB and intraoperative frozen procedure. As a minimally invasive technique, comprehensive clinical trials should be conducted to assess the value of US-guided FNAB.

\section{Acknowledgements}

Not applicable.

\section{Funding}

The present study was funded by the Guangxi Scientific Research and Technology Development Project (grant no. 14124004-1-12), The National Natural Science Foundation of China (grant no. 30960427) and The Natural Science Foundation of Guangxi (grant no. 2013GXNSFAA019235).

\section{Availability of data and materials}

The dataset supporting the conclusions of the present study is included in this article.

\section{Authors' contributions}

XH and JL conceived and designed the study. HY, WW, and YJ performed the surgery. XH collected the data and wrote this manuscript, which $\mathrm{HY}$ and $\mathrm{YJ}$ revised. $\mathrm{XZ}$ analyzed and interpreted the data. HY, WW, YJ and JL reviewed the article for important intellectual content. All authors read and approved the submitted manuscript.

\section{Ethics approval and consent to participate}

Ethical approval was obtained from the Ethics Committee for Clinical Research of The Affiliated Tumor Hospital of Guangxi Medical University (Guangxi, China), and the study itself was performed in accordance with the Declaration of Helsinki. All patients provided written informed consent.

\section{Consent for publication}

All patients provided written informed consent.

\section{Competing interests}

The authors declare that they have no competing interests.

\section{Authors' information}

Department of Breast Surgery, The Affiliated Tumor Hospital of Guangxi Medical University, Nanning, Guangxi 530021, China.

\section{References}

1. Cianfrocca M and Goldstein LJ: Prognostic and predictive factors in early-stage breast cancer. Oncologist 9: 606-616, 2004.

2. Fisher ER, Anderson S, Redmond C and Fisher B: Pathologic findings from the national surgical adjuvant breast project protocol B-06. 10-year pathologic and clinical prognostic discriminants. Cancer 71: 2507-2514, 1993.

3. Swinson C, Ravichandran D, Nayagam M and Allen S: Ultrasound and fine needle aspiration cytology of the axilla in the pre-operative identification of axillary nodal involvement in breast cancer. Eur J Surg Oncol 35: 1152-1157, 2009.

4. Giuliano AE, Hunt KK, Ballman KV, Beitsch PD, Whitworth PW, Blumencranz PW, Leitch AM, Saha S, McCall LM and Morrow M: Axillary dissection vs no axillary dissection in women with invasive breast cancer and sentinel node metastasis: A randomized clinical trial. JAMA 305: $569-575,2011$. 
5. Boland MR, Prichard RS, Daskalova I, Lowery AJ, Evoy D, Geraghty J, Rothwell J, Quinn CM, O'Doherty A and McDermott EW: Axillary nodal burden in primary breast cancer patients with positive pre-operative ultrasound guided fine needle aspiration cytology: Management in the era of ACOSOG Z011. Eur J Surg Oncol 41: 559-565, 2015.

6. Moorman AM, Bourez RL, de Leeuw DM and Kouwenhoven EA: Pre-operative ultrasonographic evaluation of axillary lymph nodes in breast cancer patients: For which group still of additional value and in which group cause for special attention? Ultrasound Med Biol 41: 2842-2848, 2015.

7. Bedi DG, Krishnamurthy R, Krishnamurthy S, Edeiken BS Le-Petross H, Fornage BD, Bassett RL Jr and Hunt KK: Cortical morphologic features of axillary lymph nodes as a predictor of metastasis in breast cancer: In vitro sonographic study. AJR Am J Roentgenol 191: 646-652, 2008.

8. Abe H, Schmidt RA, Kulkarni K, Sennett CA, Mueller JS and Newstead GM: Axillary lymph nodes suspicious for breast cancer metastasis: Sampling with US-guided 14-gauge core-needle biopsy-clinical experience in 100 patients. Radiology 250: 41-49, 2009.

9. Boughey JC, Moriarty JP, Degnim AC, Gregg MS, Egginton JS and Long KH: Cost modeling of preoperative axillary ultrasound and fine-needle aspiration to guide surgery for invasive breast cancer. Ann Surg Oncol 17: 953-958, 2010.

10. Pessoa EC, Rodrigues JR, Pessoa CP, Vespoli HM and Uemura G: Axillary lymph node aspiration guided by ultrasound is effective as a method of predicting lymph node involvement in patients with breast cancer? Rev Bras Ginecol Obstet 36: 118-123, 2014 (In Portuguese).

11. Lee MC, Eatrides J, Chau A, Han G, Kiluk JV, Khakpour N, Cox CE, Carter WB and Laronga C: Consequences of axillary ultrasound in patients with $\mathrm{T} 2$ or greater invasive breast cancers Ann Surg Oncol 18: 72-77, 2011.

12. Park SH, Kim MJ, Park BW, Moon HJ, Kwak JY and Kim EK Impact of preoperative ultrasonography and fine-needle aspiration of axillary lymph nodes on surgical management of primary breast cancer. Ann Surg Oncol 18: 738-744, 2011.

13. Baruah BP, Goyal A, Young P, Douglas-Jones AG and Mansel RE: Axillary node staging by ultrasonography and fine-needle aspiration cytology in patients with breast cancer. Br J Surg 97: 680-683, 2010.

14. van Roozendaal LM, Vane MLG, van Dalen T, van der Hage JA, Strobbe LJA, Boersma LJ, Linn SC, Lobbes MBI, Poortmans PMP, Tjan-Heijnen VCG, et al: Clinically node negative breast cancer patients undergoing breast conserving therapy, sentinel lymph node procedure versus follow-up: A Dutch randomized controlled multicentre trial (BOOG 2013-08). BMC Cancer 17: 459, 2017.

15. Cyr AE, Tucker N, Ademuyiwa F, Margenthaler JA, Aft RL, Eberlein TJ, Appleton CM, Zoberi I, Thomas MA, Gao F and Gillanders WE: Successful completion of the pilot phase of a randomized controlled trial comparing sentinel lymph node biopsy to no further axillary staging in patients with clinical T1-T2 N0 breast cancer and normal axillary ultrasound. J Am Coll Surg 223: 399-407, 2016.

16. Gentilini $\mathrm{O}$ and Veronesi U: Abandoning sentinel lymph node biopsy in early breast cancer? A new trial in progress at the European Institute of Oncology of Milan (SOUND: Sentinel node vs. observation after axillary ultrasound. Breast 21: 678-681, 2012

17. Nenutil R: A revolution postponed indefinitely. WHO classification of tumors of the breast 2012: The main changes compared to the 3rd edition (2003). Cesk Patol 51: 23-25, 2015.

18. Murray AD, Staff RT, Redpath TW, Gilbert FJ, Ah-See AK, Brookes JA, Miller ID and Payne S: Dynamic contrast enhanced MRI of the axilla in women with breast cancer: Comparison with pathology of excised nodes. Br J Radiol 75: 220-228, 2002.

19. Bonnema J, van Geel AN, van Ooijen B, Mali SP, Tjiam SL, Henzen-Logmans SC, Schmitz PI and Wiggers T: Ultrasound-guided aspiration biopsy for detection of nonpalpable axillary node metastases in breast cancer patients: New diagnostic method. World J Surg 21: 270-274, 1997.

20. Oruwari JU, Chung MA, Koelliker S, Steinhoff MM and Cady B: Axillary staging using ultrasound-guided fine needle aspiration biopsy in locally advanced breast cancer. Am J Surg 184: 307-309, 2002

21. Chang MC, Crystal P and Colgan TJ: The evolving role of axillary lymph node fine-needle aspiration in the management of carcinoma of the breast. Cancer Cytopathol 119: 328-334, 2011.
22. Kuenen-Boumeester V, Menke-Pluymers M, de Kanter AY, Obdeijn IM, Urich D and Van Der Kwast TH: Ultrasound-guided fine needle aspiration cytology of axillary lymph nodes in breast cancer patients. A preoperative staging procedure. Eur J Cancer 39: 170-174, 2003.

23. Ciatto S, Brancato B, Risso G, Ambrogetti D, Bulgaresi P, Maddau C, Turco P and Houssami N: Accuracy of fine needle aspiration cytology (FNAC) of axillary lymph nodes as a triage test in breast cancer staging. Breast Cancer Res Treat 103: 85-91, 2007.

24. Krishnamurthy S, Sneige N, Bedi DG, Edieken BS, Fornage BD, Kuerer HM, Singletary SE and Hunt KK: Role of ultrasound-guided fine-needle aspiration of indeterminate and suspicious axillary lymph nodes in the initial staging of breast carcinoma. Cancer 95: 982-988, 2002

25. Davis JT, Brill YM, Simmons S, Sachleben BC, Cibull ML, McGrath P, Wright H, Romond E, Hester M, Moore A and Samayoa LM: Ultrasound-guided fine-needle aspiration of clinically negative lymph nodes vs. sentinel node mapping in patients at high risk for axillary metastasis. Ann Surg Oncol 13: 1545-1552, 2006.

26. Leenders MW, Broeders M, Croese C, Richir MC, Go HL, Langenhorst BL, Meijer S and Schreurs WH: Ultrasound and fine needle aspiration cytology of axillary lymph nodes in breast cancer. To do or not to do? Breast 21: 578-583, 2012.

27. García Fernández A, Fraile M, Giménez N, Reñe A, Torras M, Canales L, Torres J, Barco I, González S, Veloso E, et al: Use of axillary ultrasound, ultrasound-fine needle aspiration biopsy and magnetic resonance imaging in the preoperative triage of breast cancer patients considered for sentinel node biopsy. Ultrasound Med Biol 37: 16-22, 2011.

28. Popli MB, Sahoo M, Mehrotra N, Choudhury M, Kumar A, Pathania OP and Thomas S: Preoperative ultrasound-guided fine-needle aspiration cytology for axillary staging in breast carcinoma. Australas Radiol 50: 122-126, 2006.

29. Tahir M, Osman KA, Shabbir J, Rogers C, Suarez R, Reynolds T and Bucknall T: Preoperative axillary staging in breast cancer-saving time and resources. Breast J 14: 369-371, 2008.

30. Deurloo EE, Tanis PJ, Gilhuijs KG, Muller SH, Kröger R, Peterse JL, Rutgers EJ, Valdés Olmos R and Schultze Kool LJ: Reduction in the number of sentinel lymph node procedures by preoperative ultrasonography of the axilla in breast cancer. Eur J Cancer 39: 1068-1073, 2003.

31. Gilissen F, Oostenbroek R, Storm R, Westenend P and Plaisier P: Prevention of futile sentinel node procedures in breast cancer: Ultrasonography of the axilla and fine-needle aspiration cytology are obligatory. Eur J Surg Oncol 34: 497-500, 2008.

32. MacNeill M, Arnott I and Thomas J: Fine needle aspiration cytology is a valuable adjunct to axillary ultrasound in the preoperative staging of breast cancer. J Clin Pathol 64: 42-46, 2011.

33. van Rijk MC, Deurloo EE, Nieweg OE, Gilhuijs KG, Peterse JL, Rutgers EJ, Kröger R and Kroon BB: Ultrasonography and fine-needle aspiration cytology can spare breast cancer patients unnecessary sentinel lymph node biopsy. Ann Surg Oncol 13: 31-35, 2006

34. Mainiero MB: Regional lymph node staging in breast cancer: The increasing role of imaging and ultrasound-guided axillary lymph node fine needle aspiration. Radiol Clin North Am 48: 989-997, 2010.

35. Sapino A, Cassoni P, Zanon E, Fraire F, Croce S, Coluccia C, Donadio $\mathrm{M}$ and Bussolati G: Ultrasonographically-guided fine-needle aspiration of axillary lymph nodes: Role in breast cancer management. Br J Cancer 88: 702-706, 2003.

36. Abe H, Schmidt RA, Sennett CA, Shimauchi A and Newstead GM: US-guided core needle biopsy of axillary lymph nodes in patients with breast cancer: Why and how to do it. Radiographics 27 (Suppl 1): S91-S99, 2007.

37. Koelliker SL, Chung MA, Mainiero MB, Steinhoff MM and Cady B: Axillary lymph nodes: US-guided fine-needle aspiration for initial staging of breast cancer-correlation with primary tumor size. Radiology 246: 81-89, 2008.

38. Pigott J, Nichols R, Maddox WA and Balch CM: Metastases to the upper levels of the axillary nodes in carcinoma of the breast and its implications for nodal sampling procedures. Surg Gynecol Obstet 158: 255-259, 1984.

This work is licensed under a Creative Commons Attribution-NonCommercial-NoDerivatives 4.0 International (CC BY-NC-ND 4.0) License. 